Research Article

\title{
Use of Social Media and its Effects in School Going Adolescents
}

\author{
Avula Sahithi', Shailaja V Mane ${ }^{2}$, Sharad Agarkhedkar ${ }^{3}$
}

${ }^{1}$ Resident, ${ }^{2}$ Professor and Unit Head, ${ }^{3}$ Professor \& Head, Department of Paediatrics, Dr. D.Y. Patil Medical College, Hospital and Research Centre, Dr. D.Y. Patil Vidyapeeth, Pune, Maharastra, India.

DOI: https://doi.org/10.24321/2349.2880.201910

\section{I $\quad \mathbf{N} \quad \mathbf{F} \quad \mathbf{O}$}

\section{Corresponding Author:}

Avula Sahithi, Department of Paediatrics, Dr. D.Y. Patil Medical College, Hospital and Research Centre, Dr. D.Y. Patil Vidyapeeth, Pune, Maharastra, India.

E-mail Id:

sahiti.reddy3011@gmail.com

Orcid Id:

https://orcid.org/0000-0002-0745-860X

How to cite this article:

Sahithi A, Mane SV, Agarkhedkar S. Use of Social Media and its Effects in School Going Adolescents. Ind J Youth Adol Health 2019; 6(2): 20-25.

Date of Submission: 2020-12-29

Date of Acceptance: 2020-01-21

\section{$\begin{array}{llllllll}\mathbf{A} & \mathbf{B} & \mathbf{S} & \mathbf{T} & \mathbf{R} & \mathbf{A} & \mathbf{C} & \mathbf{T}\end{array}$}

Background: Over usage of social media, has led to dependency. Dependency of youth on social media will lead to addiction. Overuse of social media has been linked to various problems like decrease in sleep hours, lack of appetite for a long time and limited physical activity leading to obesity. It can also interfere with other aspects of the daily life of an individual.

Objective: To determine the use of social media and its effects on physical health in school going adolescents.

Methods: We enrolled 412 students and questionnaire on social media usage was given to the students and physical parameters like BMI (Body Mass Index) and WHR (Waist Hip Ratio) was taken.

Result: It was observed that $60.9 \%, 19.7 \%$ and $0.7 \%$ were having mild, moderate and severe addiction, respectively, while $18.7 \%$ students were having no addiction of social media. It was seen that there were $0.9 \%$ subjects are severe underweight in boys and $0.5 \%$ in girls. $0.4 \%$ boys and $2.1 \%$ girls were underweight. $61.3 \%$ subjects were normal in boys and $70.1 \%$ in girls. $24.4 \%$ subjects were overweight in boys and $20.9 \%$ in girls. $12.9 \%$ subjects were obese in boys and $6.4 \%$ in girls. The waist-hip ratio was observed to be increasing from $0.82 \pm 0.07$ among students having no addiction to $0.83 \pm 0.08$ in mild addiction students and $0.88 \pm 0.07$ in moderate addiction students which is statistically significant.

Conclusion: Majority of the students (60.9\%) were having mild social media addiction. There was significant association observed in severity of addiction and waist-hip ratio, which might lead to obesity and other non-communicable diseases in later life.

Keywords: Social Media, Over Usage, Physical Health, BMI, WHR

\section{Introduction}

India, which is a developing country, holds third place in Internet usage in the world, and has highest use of mobiles and social media. Having social media account is easy these days and today 2.5 billion people across the world have their profiles in social media; active social media users were 197 million (14\% of the population) in India. ${ }^{1}$ Communication has undergone a complete transformation with the advent 
of social media. Social media is one of Internet-based media that allows people to interact with each other without having to meet face to face. It has become a new set of tools for involving young peoples. Youngsters are in conversation and communication not only with their friends and groups by using different media and devices every day but also with unknown people through social media. Nowadays, irrespective of their socioeconomic background, adolescents have greater exposure to electronic gadgets like smartphones at a much younger age, and hence, more prone to social media overuse or addiction. Shapiro and Margolin² found that $73 \%$ or more of all adolescents are using social media. The idea of social media seems to be wonderful, but it is the constant use and physical and psychological harm that makes social media use dangerous. On average, 11 to 18 years adolescents spend over 11 hours a day exposed to electronic media. ${ }^{3}$

Adolescents are a unique population with specific health concerns and needs. Physical inactivity is estimated to cause approximately 3.2 million deaths globally each year. ${ }^{3}$ Numerous American and international longitudinal studies (one of them as long as 26 years in duration) have shown that media use is contributing to the current epidemic of obesity worldwide. ${ }^{4}$ According to Aparajita Dasgupta ${ }^{5}$ highscreen time has 3.56 times the risk of obesity as compared to low-screen time in students. The high-screen time is indirectly increasing the physical inactivity which in turn increases BMI and WHR, leading to obesity. ${ }^{5}$

Apart from preventing excessive media use, physical activity during media use is also a subject of concern. Hence, there is need to study the use of social media and its effects on physical health and preventing them by encouraging physical activity, limiting social media use and having recommended sleep which can prove beneficial for health.

\section{Methods}

After institutional ethics and committee clearance, the proposed study was conducted for 2 years by the Department of Paediatrics of Tertiary Care Institute, Pune. It was prospective cross-sectional study. 412 students between the age of 13 and 15 years were the study group. Adolescents who were apparently healthy students without any chronic illness and whose consent from parents and assent from students for answering questionnaire is given are included. Adolescents belonging to age group more than 15 years and age group less than 13 years, adolescents suffering from endocrine disorder, chronic diseases and cardiovascular, respiratory, musculoskeletal, renal diseases and adolescent whose parents are not willing for participation in the study and whose assent for answering questionnaire was not given were excluded from the study.

\section{Study Tools}

A self-reported questionnaire was used to collect data, about the adolescent's usage of social media along with physical parameters. History of chronic diseases along with diet, sleep, addictions, physical activity and other habits were duly noted. A valid and reliable scale for usage of social media among adolescents in English "Social Media Addiction Scale-Student Form" (SMAS-SF) was used, after taking permission of the author for the usage of questionnaire for the study. Scoring of SMAS-SF was done by Quartile method where the minimum score is 29 and maximum score is 145 and Social Media addiction scores were distributed as: No addiction (29-58), Mild (59-87), Moderate (88-116), and Severe (117-145).

The objectives of the study were explained to all the students, and then questionnaires were given to them to complete and were collected after completion. The researcher (Second author) was present throughout the data collection and students were clarified of their doubts during the data collection. After finishing the filling of questionnaire, physical parameters (height, weight, BMI, WHR) were taken for each student by the investigator following standard operative procedures. A female resident was present for examining the girls and male resident was present for examination of boys.

The scores of SMAS-SF were calculated. Students with mild, moderate and severe addiction were noted and correlated with their physical parameters. The parents of these students were contacted through the school management and advised to visit the study institute for expert opinion and counseling of adolescents in adolescent super specialty clinic. Those students were referred for further management and life-skill education sessions.

\section{Methodology for Measuring Anthropometric Measurements}

- Weight: All adolescents were weighed with minimum appropriate clothes using standard technique and electronic weighing scale with a precision of $10 \mathrm{~g}$. The student was asked to stand in the middle of scale, feet slightly apart and to remain still until weight appeared on display. ${ }^{6}$

- Height: Height was measured using standard technique by using stadiometer. "The student is made to stand on baseboard with feet slightly apart. The back of the head, shoulder blades, buttocks, calves, and heels should all touch the vertical board. Position student's head so that a horizontal line from the ear canal to lower border of eye socket runs parallel to the baseboard. To keep head in this position, hold the bridge between your thumb and forefinger over student's chin." 7 The line of vision was straight and parallel to the floor.

- Body Mass Index: Body mass index (BMI) was calculated using standard formula of BMI= Weight in kgs/(height in $\mathrm{m}),{ }^{2} \mathrm{Z}$ scores were calculated using standard formula 
of Z score=(observed value - mean for the appropriate age and gender)/(Standard Deviation). IAP 2015 growth reference data was used to obtain the mean values and SD for the appropriate age and gender. The cutoffs used for categorizing children as underweight, normal, overweight and obese were as defined by IAP 2015 references (For boys $\mathrm{Z}$ score $<-1.88$ is underweight, between -1.88 and 0.54 is normal, between 0.54 and 1.28 is overweight and $>1.28$ is obese. For girls $Z$ score $<-1.88$ is underweight, between -1.88 and 0.67 is normal, between 0.67 and 1.64 is overweight and $>1.64$ is obese).

- Waist Circumference: It was measured by a nonstretchable measuring tape, midway between the lowest rib and superior border of iliac crest at the level of umbilicus without compressing the skin at the end of normal expiration in standing position with weight equally balanced on both feet.

- Hip Circumference: It was recorded at the maximum girth or widest portion of hip with precautions similar to waist circumference (in Inch).

- Waist: Hip Ratio: Classified using WHO Asian charts. Waist hip ratio more than $95^{\text {th }}$ centile was considered. There are no standard charts (WHR charts) available for adolescents, so adult cut off values were taken as reference. WHR range: Normal (Boys $<0.90$, girls $<0.85$ ), Obesity (Boys .0.90, Girls >0.85)

\section{Statistical Analysis}

The data entry was done in Microsoft Excel and Data analysis was done using the SPSS (Statistical Package for the Social Science) Version 17 for window. The demographic variable-social media addiction was calculated with number and percentage. $Z$ score was calculated for BMI. Correlation and Z-test for correlation was used to find the correlation between social media addiction, BMI and WHR. A probability value ( $p$ ) less than 0.05 was accepted as the level of statistical significance.

\section{Result}

In the present study majority of the school going students were 14 years old (43.7\%) followed by 15 years $(28.4 \%)$ and 13 years $(27.9 \%)$ (Table 1$)$. It was seen that $54.6 \%$ students were boys and $45.4 \%$ were girls with boy: girl ratio of $1.20: 1$ (Table 2). It was observed that $18.7 \%$ students were not having addiction (29-58) of social media. While $60.9 \%$ were having mild addiction (59-87) and $19.7 \%$ were having moderate addiction (88-116). Among them $0.7 \%$ (117-145) were having severe addiction (Table 3). It was seen that $0.9 \%$ subjects are severe underweight in boys and $0.5 \%$ in girls. $0.4 \%$ subjects were underweight in boys and $2.1 \%$ in girls. $61.3 \%$ subjects were normal in boys and $70.1 \%$ in girls. $24.4 \%$ subjects were overweight in boys and $20.9 \%$ in girls. $12.9 \%$ subjects were obese in boys and $6.4 \%$ in girls (Table 4). It was seen that $33.3 \%$ subjects were abnormal and $66.7 \%$ were normal in boys while in girls $26.7 \%$ subjects were abnormal and $73.3 \%$ were normal (Table 5). The mean BMI of students with mild social media addiction was $19.69 \pm 4.119$ while that of moderate and severe addiction was $19.98 \pm 3.580$ and $22.12 \pm 5.346$, respectively. The difference observed was not statistically significant ( $p=0.43$ ) (Table 6, Figure1).

The waist: hip ratio was observed to be increasing from $0.82 \pm 0.07$ among students with no addiction to $0.83 \pm 0.08$ in mild addiction students and $0.88 \pm 0.07$ in moderate addiction students. The difference observed in the waist hip ratio was statistically significant $(p<0.0001)$ (Table 7 , Figure 2).

Table I.Age wise distribution of cases in study

\begin{tabular}{|c|c|c|}
\hline Age (Yrs.) & No. of cases & Percentage \% \\
\hline 13 & 115 & 27.9 \\
\hline 14 & 180 & 43.7 \\
\hline 15 & 117 & 28.4 \\
\hline Total & 412 & 100.0 \\
\hline
\end{tabular}

Table 2.Sex wise distribution of cases in study

\begin{tabular}{|c|c|c|}
\hline Sex & No. of cases & Percentage $\%$ \\
\hline Boys & 225 & 54.6 \\
\hline Girls & 187 & 45.4 \\
\hline Total & 412 & 100.0 \\
\hline
\end{tabular}

Table 3.Social media addiction wise distribution of cases in study

\begin{tabular}{|c|c|c|}
\hline Social Media addiction & $\begin{array}{c}\text { No. of } \\
\text { cases }\end{array}$ & Percentage \% \\
\hline No Addiction (29-58) & 77 & 18.7 \\
\hline Mild (59-87) & 251 & 60.9 \\
\hline Moderate (88-116) & 81 & 19.7 \\
\hline Severe (117-145) & 3 & 0.7 \\
\hline Total & 412 & 100.0 \\
\hline
\end{tabular}

Table 4.Body Mass Index wise distribution of cases in study

\begin{tabular}{|c|c|c|c|}
\hline BMI & Boys (\%) & Girls (\%) & Total (\%) \\
\hline $\begin{array}{c}\text { Severe } \\
\text { underweight }\end{array}$ & $2(0.9)$ & $1(0.5)$ & $3(0.7)$ \\
\hline Underweight & $1(0.4)$ & $4(2.1)$ & $5(1.2)$ \\
\hline Normal & $138(61.3)$ & $131(70.1)$ & $269(65.3)$ \\
\hline Overweight & $55(24.4)$ & $39(20.9)$ & $94(22.8)$ \\
\hline Obese & $29(12.9)$ & $12(6.4)$ & $41(10)$ \\
\hline Total & $225(100)$ & $187(100)$ & $412(100)$ \\
\hline
\end{tabular}


Table 5.Waist:Hip Ratio wise distribution of cases in study

\begin{tabular}{|c|c|c|c|}
\hline WHR (Boys) & No. of cases (\%) & WHR (Girls) & No. of cases (\%) \\
\hline Abnormal $(>0.90)$ & $75(33.3)$ & Abnormal $(>0.85)$ & $50(26.7)$ \\
\hline Normal $(<0.90)$ & $150(66.7)$ & Normal $(<0.85)$ & $137(73.3)$ \\
\hline Total & $225(100)$ & Total & $187(100)$ \\
\hline
\end{tabular}

Table 6.Comparison of Body Mass Index according to social media addiction in study group

\begin{tabular}{|c|c|c|c|c|c|}
\hline \multirow{2}{*}{$\begin{array}{c}\text { Social media } \\
\text { addiction }\end{array}$} & \multicolumn{3}{|c|}{ Body Mass index } & \multirow{2}{*}{ f-value } & p-value \\
\cline { 2 - 4 } & $\mathbf{N}$ & Mean & SD & & \\
\hline No addiction & 77 & 20.35 & 3.53 & & \\
\hline Mild & 251 & 19.69 & 4.11 & \multirow{2}{*}{0.92} & \multirow{2}{*}{0.43} \\
\hline Moderate & 81 & 19.98 & 3.58 & & \\
\hline Severe & 3 & 22.12 & 5.34 & & \\
\hline
\end{tabular}

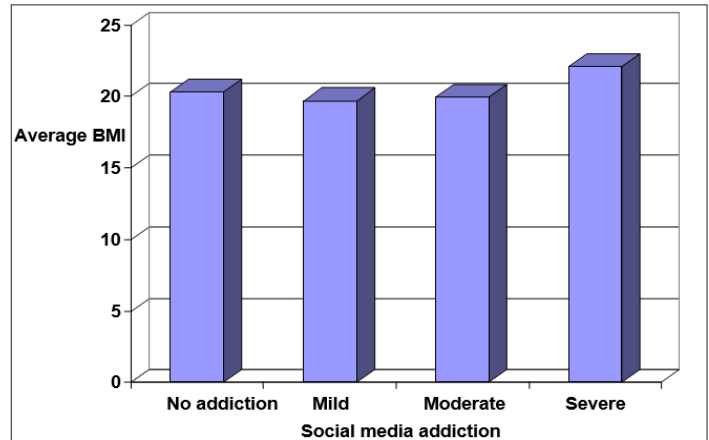

Figure I.Bar diagram showing comparison of Body Mass Index according to social media addiction in study

Table 7.Comparison of Waist hip ratio according to social media addiction in study

\begin{tabular}{|c|c|c|c|c|c|}
\hline \multirow{2}{*}{$\begin{array}{l}\text { Social media } \\
\text { addiction }\end{array}$} & \multirow[b]{2}{*}{$\mathbf{N}$} & \multicolumn{2}{|c|}{ Waist hip ratio } & \multirow{2}{*}{ f-value } & \multirow{2}{*}{ p-value } \\
\hline & & Mean & SD & & \\
\hline No addiction & 77 & 0.82 & 0.07 & \multirow{4}{*}{11.97} & \multirow{4}{*}{$<0.0001$} \\
\hline Mild & 251 & 0.83 & 0.08 & & \\
\hline Moderate & 81 & 0.88 & 0.07 & & \\
\hline Severe & 3 & 0.86 & 0.17 & & \\
\hline
\end{tabular}

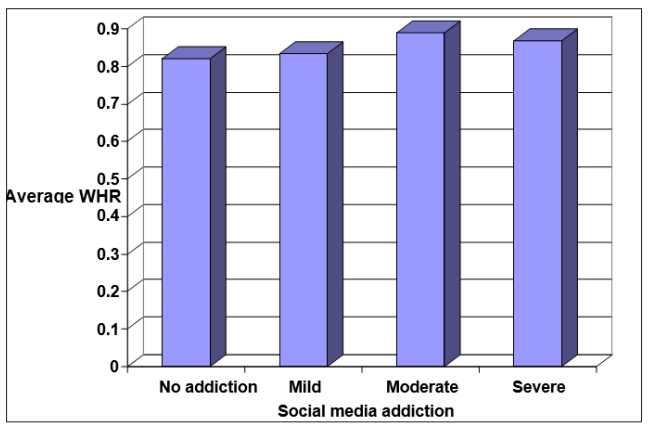

Figure 2.Bar diagram showing comparison of Waist hip ratio according to social media addiction in study group

\section{Discussion}

The present study was conducted to evaluate the use of social media and its effects in school going adolescents. Total 412 students were from the private coeducation CBSE syllabus school in Pimpri Chinchwad Urban area, most of them belonging to middle class, were enrolled in the present study and were evaluated.

In the present study majority of the school going students were of 14 years old (43.7\%) followed by 15 years $(28.4 \%)$ and 13 years $(27.9 \%)$ (Table 1 ). It was seen that $54.6 \%$ were boys and $45.4 \%$ were girls with boy:girl ratio of 1.2:1 (Table 2).

In the present study, Social Media Addiction Scale: Student Form (SMAS-SF) was used to assess the social media addiction among students along with physical parameters.

\section{Social Media Addiction}

It was observed $60.9 \%$ were having mild addiction (59-87) and $19.7 \%$ were having moderate addiction (88-116) while $18.7 \%$ students were with no social media addiction (2958). Only $0.7 \%$ had severe addiction (117-145) (Table 3). Masthi, et $\mathrm{al}^{8}$ studied the social media addiction among the students and observed mild addiction among $72.7 \%$ and moderate addiction among $25.7 \%$ students. Thus, the findings were comparable with the present study. In contrast, Azizi et al. ${ }^{9}$ reported that moderate addiction $(70.6 \%)$ in majority of students followed by mild addiction (15.8\%) was observed. As majority of our study belonged to middle class and Internet access for usage of social media is limited, most of the students were found to fall under mild addiction. Thus, the addiction to social media and Internet is increasing among the adolescents. The utilization of social media has become an integral part of Indian adolescents and youth today. The dependency of youth on the social media has reached at such level that, without social media, the youth cannot think about the direction of their growth.

\section{Physical parameters (Body Mass Index, Waist: Hip Ratio)}

It was seen that $0.9 \%$ subjects are severely underweight in boys and $0.5 \%$ in girls. $0.4 \%$ subjects are underweight in boys and $2.1 \%$ in girls. $61.3 \%$ subjects were normal in boys and $70.1 \%$ in girls. $24.4 \%$ subjects were overweight in boys and $20.9 \%$ in girls. $12.9 \%$ subjects were obese in boys 
and $6.4 \%$ in girls (Table 4). It was seen that Waist:Hip ratio of $33.3 \%$ subjects was abnormal $(>0.90)$ and $66.7 \%$ were normal $(<0.90)$ in boys while in girls $26.7 \%$ subjects were abnormal (0.85) and 73.3\% were normal (<0.85) (Table 5).

\section{Association of Physical Parameters (Body Mass Index and Waist: Hip Ratio) with Social Media addiction}

The mean BMI of students with mild social media addiction was $19.69 \pm 4.119$ while that of moderate and severe addiction was $19.98 \pm 3.580$ and $22.12 \pm 5.34$, respectively. The difference observed was not statistically significant $(p=0.43)$ (Table 6, Figure1).

The waist: hip ratio was observed to be increasing from $0.82 \pm 0.07$ among students with no addiction to $0.83 \pm 0.08$ in mild addiction students and $0.88 \pm 0.07$ in moderate addiction students. The difference observed in the waist: hip ratio was statistically significant $(p<0.0001)$, showing an increasing trend pointing towards obesity (Table 7, Figure 2). Though there was no significant difference observed in BMI, the adolescents would further have an increased $\mathrm{BMI}$ in future due to sedentary lifestyle and further studies are required.

Datis Khajeheian et al. ${ }^{10}$ study illustrates that increased daily use of social media is independently associated with greater BMI levels for high school students. Griffiths and Page ${ }^{11}$ mentioned that obesity has been related to victimization and social isolation. Using technology like social media may promote sedentary lifestyle and replace otherwise active behaviors, and may thus contribute to energy imbalance which is a concern.

\section{Conclusion}

Majority of the students in this study (60.9\%) were having mild social media addiction, $19.7 \%$ were having moderate addiction and $0.7 \%$ were having severe addiction. There was significant association observed in severity of addiction and waist:hip ratio, which might lead to obesity and other non-communicable diseases in later life.

\section{Recommendation}

Awareness programs for safe use of social media, negative impacts of social media addiction on physical, behavioral and social health (e.g., reduced physical activity, disturbed sleep, increased consumption of junk food, decreased social interaction, etc.) should be arranged at school and community levels. Adolescent stakeholders (parents, teachers, pediatricians, etc.) should take care of prevention and early detection of social media addiction by increasing awareness of ill effects of social media addiction, promoting healthy lifestyle and life skills education to all. Internet service providers and other concerned competitive authorities should look into the matter of negative effects of social media on young generation, to provide a better environment to the young users.

\section{Conflict of Interest: None}

\section{References}

1. Tech in Asia - Connecting Asia's startup ecosystem [Internet]. Techinasia.com. 2019 [cited 23 October 2019]. Available from: https://www.techinasia.com/ india-462-million-internet-users-79-traffic-mobile

2. Shapiro LAS, Margolin G. Growing up wired: social networking sites and adolescent psychosocial development. Clinical Child and Family Psychology Review 2014; 17(1): 1-18. Available from: https://link. springer.com/article/10.1007\%2Fs10567-013-0135-1 [PubMed/ Google Scholar].

3. Alwan A. Global status report on noncommunicable diseases 2010. World Health Organization; 2011. Available from: https://www.who.int/nmh/publications /ncd_report2010/en/.

4. Jordan A, Kramer-Golinkoff E, Strasburger V. Do the media cause obesity and eating disorders? Adolesc Med State Art Rev 2008; 19(3): 431-449. [PubMed/ Google Scholar].

5. Dasgupta A, Karmakar A, Bandyopadhyay L, Garg S, Paul B, Dey A. How vulnerable are our adolescents to noncommunicable diseases? A school-based study in Kolkata. Int J Health Allied Sci 2017; 6(4): 199-203. Available from: http://www.ijhas.in/article. asp?issn=2278-344X;year=2017; volume=6;issue=4; spa ge=199; epage=203; aulast=Dasgupta [Google Scholar] .

6. World Health Organization. weight a child alone; Training Course on Child Growth Assessment. WHO Child Growth Standards. Geneva: WHO; 2008; 18-21.

7. World Health Organization. measure standing height; Training Course on Child Growth Assessment. WHO Child Growth Standards. Geneva: WHO; 2008. 23-25.

8. Ramesh Masthi NR, Pruthvi S, Phaneendra MS. A comparative study on social media usage and health status among students studying in pre-university colleges of urban Bengaluru. Indian J Community Med 2018; 43: 180-184. Available from: http://www.ijcm. org.in/article.asp?issn=0970-0218; year=2018; volum $\mathrm{e}=43$; issue $=3$; page $=180$; epage $=184$; aulast $=$ Ramesh [PubMed/ Google Scholar].

9. Azizi SM, Soroush A, Khatony A. The relationship between social networking addiction and academic performance in Iranian students of medical sciences: a cross-sectional study. BMC Psychol 2019; 7(1): 28. Available from: https://bmcpsychology.biomedcentral. com/articles/10.1186/s40359-019-0305-0 [PubMed/ Google Scholar]. 
10. Khajeheian D, Colabi AM, Shah NBAK, Jasimah CW, Radzi BWM Jenatabadi HS. Effect of Social Media on Child Obesity: Application of Structural Equation Modeling with the Taguchi Method. Int J Environ Res Public Health 2018; 15: 1343. Available from: https:// www.mdpi.com/1660-4601/15/7/1343 [PubMed/ Google Scholar].

11. Griffiths LJ, Page AS. The impact of weight-related victimization on peer relationships: The female adolescent perspective. Obesity 2008; 16: S39-S45. Available from: https://onlinelibrary.wiley.com/doi/ full/10.1038/oby.2008.449 [PubMed/ Google Scholar]. 